\title{
Trends in the Social Responsibility Expenditures of Small and Medium Enterprises from Oradea
}

\author{
Tomina Saveanu \\ University of Oradea - Faculty of Economics \\ tsaveanu@uoradea.ro \\ Conf. Univ. Dr. Maria-Madela Abrudan \\ University of Oradea - Faculty of Economics \\ mabrudan@uoradea.ro
}

\section{Doi:10.5901/mjss.2015.v6n2s5p212}

\begin{abstract}
In the context of corporate social responsibility studies there is a gap in understanding these actions at small and medium enterprises (SME). The processes stimulating social expenditures and the motivations in doing so at this level would provide useful information in explaining this phenomenon. At large corporations CSR is part of strategies, there are employees dealing with it managing CSR budgets. However only in smaller enterprises we can understand the decisions to invest in social actions, the domains of such actions and their perceived impact. Our analysis investigates the social expenditures in the form of donations and sponsorship registered by SMEs reporting profit in Oradea. The data was extracted from the National Agency of Fiscal Administration regarding expenditures of small and medium enterprises in 2013. There are $20 \%$ of all SMEs that declare such costs, a percentage that we consider is significant for this phenomenon. In this paper, we explore the extent to which these investments vary depending on the size of the enterprise (measured as business rate and number of employees), profit and domain. As expected the bigger the firm, the higher are the chances to donate money and also the amount donated is higher. Future studies should focus on qualitative data mostly motivations of such expenditures.
\end{abstract}

Keywords: corporate social responsibility, social involvement, small and medium enterprises

\section{Introduction}

The interest regarding the social involvement of companies has reached high levels in the last years, even if from a research standpoint the benefits can be contested (McWilliams et al. 2005). Practitioners are interested mainly in the effects of such actions for the companies, while lobbyists and policy makers are interested in the community level effects. Beyond the many controversies regarding to which forms of involvement are most important, there is a general agreement that enterprises can contribute positively to development.

Donations and sponsorship are considered at the top of social responsibility actions, as a concrete and specific form of involvement. Other forms include different level policies (environmental protection, human resources, customer relations, etc. ) and actions towards the satisfaction of requests of different stakeholders. Social responsibility is traditionally associated to large companies, multinational corporations however several studies reveal that this is an attitude which may characterize all type of organizations: large and small, public and private, governmental and nongovernmental.

In this paper we focus on one of the classical forms of social responsibility of firms - the expenditures for social causes from small and medium enterprises (SME) in Oradea - Bihor County, Romania. This topic is a part of a postdoctoral study regarding the social involvement of Romanian organizations, study in which we try to identify both the forms of such actions, as well as their causes and obstacles. So far we have observed significant information that for Romania it is important to analyze these processes for small and medium companies. Mechanisms that trigger social involvement for these firms can hinder ways to promote such attitude from all companies. More, there is some evidence that the motivations and forms of social involvement of smaller companies bring closer theories of CSR to the one of individual community participation. Active citizenship is a concept that bridges the two directions as it widens the contexts in which social involvement takes place.

The analysis of this article started with the main question - is there enough evidence of social activity of SMEs? 
Due to the availability of data we restricted our analysis to Oradea as we expect that in this regard the differences between counties should not be very large. More, knowing the fiscal facility regarding the deduction of taxes for donations or sponsorship we limited the search for evidence of social involvement of small and medium enterprises in Oradea, Bihor county to this form of action. We are aware that there are other ways SMEs may get involved in their community, however this is one of the key forms considering CSR theory, and thus defining for this phenomenon. The first question this paper is answering is to what extent small and medium enterprises from Oradea donate money as social involvement actions? More, aiming at the characterization of this process we answered to the second question: which are the firm level characteristics that stimulate such actions?

\section{Social Responsibility: Discourse or Reality?}

\subsection{General framework}

Social responsibility of organizations can be considered a new paradigm regarding business-society relationship (Saveanu et. al. 2014). The topic has gained high notoriety in the last two decades both from theoretical and practical perspectives. Nonetheless theoreticians did not yet reach full consensus regarding the concepts used (corporate social responsibility or performance, corporate citizenship, corporate sustainability and the list can continue) as well as regarding what constitutes social behavior on behalf of organizations (Aguinis and Glavas, 2012). The most widely used concept remains corporate social responsibility (CSR) and the distinctions between this and other terms are not that clear-cut. In this paper we will refer to CSR, acknowledging that such social attitude can be observed generally in organizations private as well as public, large as well as small (Acar et. al. 2001).

We are considering a narrow definition of CSR as "actions that appear to further some social good, beyond the interests of the firm and that which is required by law" (McWilliams et. al. 2005, p. 3). A classical, yet broader, approach was developed by Carroll $(1979,1991)$ comprising all economical, legal, ethical and discretionary responsibilities of a company. We consider that the first two are mandatory to all firms and as such should not be considered when deciding when a company is socially responsible and not. Even following such an approach CSR can be contested as being purely discourse in the form of PR propaganda or another form of domination of large companies (Banerjee, 2007). The difficulties in assessing the impact (Barth et. al. 2007) rise also questions regarding which actions are relevant in considering social responsibility and also which are the more profitable investments for companies as well as for society as a whole (Knox şi Maklan, 2004).

Measuring CSR is one of the core problems and a requiring critic within this topic. It starts with deciding which actions can be considered socially responsible ranging from mission statements to direct involvement in community programs. Some theoreticians argue that the motivations behind each action are the ones that make the difference between opportunists and "true" CSR, however practitioners consider that it should be a win-win context. If we disregard the reasons behind such actions one of the areas which does not raise question marks whether it represents or not social responsibility is represented by offering money to charities or social campaigns. Donations and sponsorships are at the top of CSR pyramid (Carroll, 1991). This is the level of CSR we focus on in this paper: the donations offered by small and medium enterprises in Bihor County. Information regarding the destination of this money was not available and consequently it is impossible to discuss the impact of these payments. More, qualitative data is needed in order to clarify the motivations behind these investments and the choice for the beneficiaries.

Regarding the factors that stimulate social responsibility the literature highlights both subjective (manager level factors such as motivations and attitudes) and objective factors. Lindgreen (2009) shows that the interests regarding different stakeholders changes depending the level of development of the firm. At the begging, with few employees and lower incomes, companies will be interested in primary stakeholders (such as clients), however as the company grows it integrates social objectives into its strategy and invests systematically in these actions. Consequently we will expect that this trend can be observed when analyzing small and medium enterprises (up to 250 employees), as we are investigating the relationship between the decision to donate money and the size of the firm.

\subsection{CSR policy in Romania in the European context}

European Commission uses the concept of social responsibility of enterprises as a larger context then corporate social responsibility. The definition is derived from the narrow approach of CSR as the "capacity of enterprises to voluntarily take up actions, beyond their legal obligations, to achieve social and environmental objectives in their everyday activity" [authors' translation based on the definition posted on http: //ec. europa. eu/social/main. jsp?langld=ro\&catld=331 ]. 
However the levels considered by the Commission as relevant for enterprises in this matter are structured on the legal which is mandatory and voluntary: "integrating social, environmental, ethical, consumer, and human rights concerns into their business strategy and operations" (http: //ec. europa. eu/growth/industry/corporate-social-responsibility/index_en. $\mathrm{htm})$.

There are several documents assumed or agreed upon by the European Commission regarding CSR. These include policies promoting social responsibility of enterprises in Europe (Green papers and Strategies of CSR), standards and performance parameters (ISO 26000 Guidance Standard on Social Responsibility), evaluations and comparisons of achievement of these standards and the objectives set in the strategies.

Within the European frame, the social responsibility of small and medium enterprises was considered a priority of the European Alliance on CSR (COM (2006) 136). In the light if this approach SMEs are considered to have a great role in sustaining a responsible business environment and as promoters of such an attitude. However in consequent evaluations it was noted that the impact of CSR policy on SMEs is small as their social actions will be inconsequent and unintegrated in a strategic approach. Consequently the impact of such actions will be less relevant then those of large companies and programs proposed by alliances (COM (2011) 186). Nonetheless we consider that the European focus on SMES' CSR provide enough context for furthering research on this topic. Consequently we reflect in our study some of the efforts made in this regard by SMEs in Oradea, namely in the form of donations or sponsorship.

Through the European level studies and assessments of CSR impact, some conclusions regarding Romania can be drawn. Up to last year, comparative studies reveal the lack of maturity mostly by Romanian agencies in fostering CSR initiatives but also by Romanian business in engaging in such actions. Even if several steps were undertaken with the elaboration of a national strategy and the initiation of specific actions, these are fragmented, lack transparency, are dependent on external funding and are insufficiently monitored and reported (Williamson et. al. 2014). As such, the National strategy for promoting social responsibility (2011) has little visibility and was not translated into concrete action plans and steps towards its implementation. This strategy (2011) defines the national priorities in a wide range of domains from social security to work, environment and education. Both the priorities and the strategic objectives have a high degree of generality which make them harder to measure. The action plan presented in the end of this strategy defines general guidelines on each priority and sets responsibility areas; however it lacks concrete steps to be undertaken by each identified actor and, as so many other similar documents in Romania, remains without practical applicability.

If one considers the narrow view of CSR, the legal aspects are relevant if considered as facilities meant to stimulate such actions and not the mere obedience to the law. As such, in Romania there are several fiscal initiatives for enterprises meant to stimulate social actions. There are also more targeted initiatives regarding employment/human capital or the environment but these are not the object of the current analysis. We refer mostly to the Fiscal Code by which people can direct $2 \%$ of their taxes to a specific NGO (art. 84 (2)- (3)) or the deduction of $20 \%$ of the due tax of amounts offered as sponsorship or donations (art. 21, lit. p). These mechanisms stimulate directly enterprise philanthropy - the top of Carroll's pyramid (1991). The promotion of these mechanisms in Romania is conducted mainly by the beneficiaries of such initiatives / NGOs whose activities can be financially supported with these sums.

In our analysis we focus on the latter instrument, the deduction of $20 \%$ of taxes for donations, aiming at the assessing the impact at small and medium enterprises in Oradea. More, we will also analyze the profile of the enterprises undertaking such investments.

\section{Social Responsibility of Small and Medium Enterprises in Oradea}

\subsection{Research methodology}

The objectives of this paper, were both to assess the extent to which small and medium enterprises use the fiscal facility of deducting up to $20 \%$ of taxes as donations or sponsorship, and also to analyze the profile of the SMEs which declare such costs. In order to achieve these objectives we analyzed data provided by the National Agency of Fiscal Administration regarding expenditures of small enterprises in 2013. We considered companies which registered profit as only these can deduct taxes as donations. The available data in order to have a homogenous sample included the whole population of small and medium enterprises.

The main data reflects the amount of money offered as donation or sponsorship. In order to create the profile of companies which have social investments, we collected also data regarding the size of the enterprise: number of employees, profit and turnover. Unfortunately there was no data available regarding the destination of donated money, data that would shape the profile of social investments of small companies. 


\subsection{Main conclusions}

Out of the total 14. 562 active SMEs registered in Bihor county in 2013 (according to the National Institute of Statistics: http: //statistici. insse. ro/shop/), there are 2782 which declared profit to the Agency of Fiscal Administration. As presented in Figure no. 1, 18\% offer different amounts as sponsorship or donations.

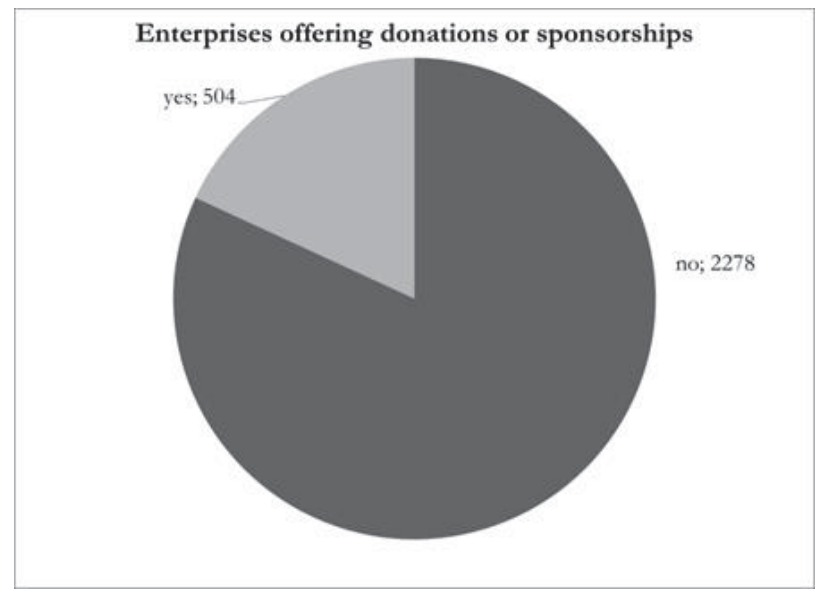

Figure no. 1. Number of small enterprises from Bihor County offering donations, Agency of Fiscal Administration, own calculations

Even if this percentage seems rather small (and 3,4\% is even smaller when reported to the total number of small enterprises), we consider that it is significant for social responsibility of these enterprises. This finding supports previous conclusions regarding the openness of micro and small enterprises in Romania towards social responsibility actions (Saveanu et. al. 2014). We thus reinforce the conclusion that CSR of SMEs is an understudied phenomenon that should gain more attention by researchers.

The average money donated is of 2685 lei, about 600 euros. The data reefing the profile of donations is presented in table 1 and the normal distribution of the sums offered as donations can be observed in figure no. 2. Unfortunately there was no data regarding the destination of this money: NGO's, campaigns, or individuals. This type of information is fundamental in a creating a complete picture of social actions supported by these firms.

Figure no. 2. The distribution of donations offered by small enterprises from Bihor County offering donations, Agency of Fiscal Administration, own calculation

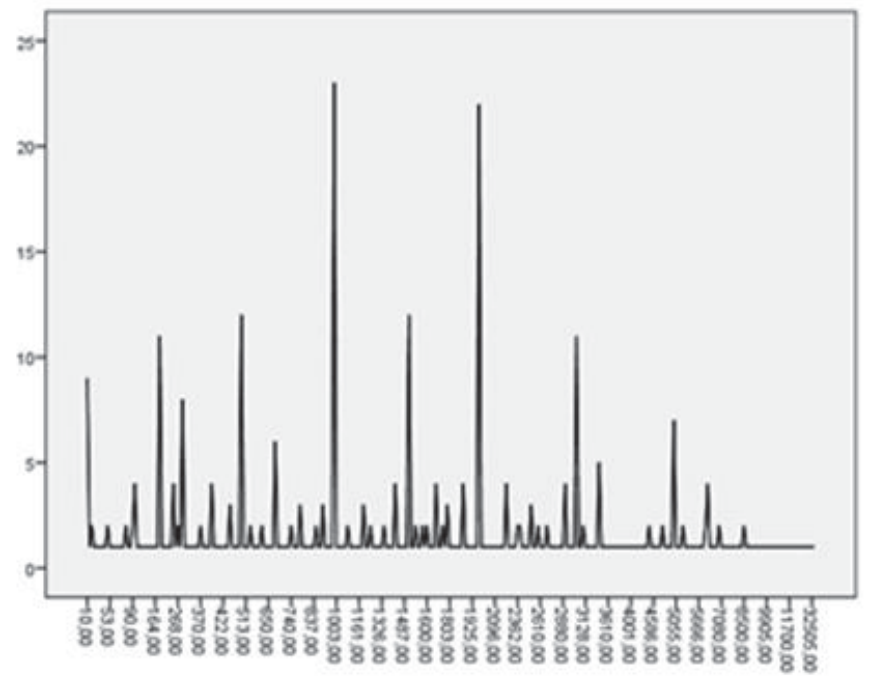


Table no. 1. Description of donations offered by small enterprises from Bihor County offering donations, Agency of Fiscal Administration, own calculations

\begin{tabular}{|c|c|}
\hline No. Cases & 504 \\
\hline Mean & 2685,35 \\
\hline Std. Deviation & 3821,83 \\
\hline Minimum & 10,00 \\
\hline Maximum & 37814,00 \\
\hline Sum & 1353417 \\
\hline
\end{tabular}

Turning to the profile of the enterprises which financially support social actions, we investigated one of the classical determinants of CSR: size of the enterprise (Lindgreen et. al. 2009). Consequently we tested the relationship between the donated amounts and number of employees, profit, and turnover.

All three considered independent variables considered significantly correlate with the donations and sponsorship: turnover $(p=0.681, s i g=0.00)$, profit on reference year $(p=0.586$, sig $=0.00)$ and number of employees during the reference year $(p=0.139$, sig $=0.00)$. These data support the conclusion that the amounts donated by companies are increase along with the increase in profit, turnover and number of employees: as a firm is growing so are the chances it will display this form of social responsibility.

More, regarding the influence of profit we could investigate also rather there are differences between the forms that donate and those that do not. Again, through T-test we can highlight a positive relation: the average profit is significantly higher for the companies who donate money than those that do not ( $F=1$. 74; equal variances not assumed; sig. $=0.00)$.

We need to compare the group of SMEs to large companies, and to make comparative analysis between the group of small vs. medium enterprises in order to generalize this conclusion. At this point we have found important evidence that within the small enterprises the social responsibility actions are influence by the level of development of the firms.

\section{Conclusions}

We can say that the incidence of the fiscal facility regarding tax deduction for donations and sponsorship is of $18 \%$ among the profit gaining small and medium enterprises in Bihor County. The factors facilitating such actions on behalf of enterprises are the profit, turnover and number of employees. Both the existence of donations, and the amount spent in this manner are influenced by these aspects related to the size of the firm - the richer and larger a small firm chances increase to donate, and the sums increase along with the development of such firms.

As mentioned above, this conclusion was validated solely for the small and medium enterprises and further analysis should extend the comparison with large enterprises. Nonetheless there is evidence to suggest the same pattern in general. Another limit is the result of the lack of information regarding the destination of this money. In order to complete the image regarding social responsibility actions at the top of Carroll's CSR pyramid we need information regarding the actions that are actually funded through these donations and more information on how where these social actions chosen.

This paper fills in an important gap in the knowledge regarding CSR in Romania, as well as CSR within SMEs. The main conclusion is that within these enterprises there is an important orientation towards social actions which need to be understood better. More, understanding the mechanisms that stimulate the investment in social actions at the level of small enterprises would improve our knowledge regarding these processes and consequently would highlight methods for promoting social involvement of companies.

\section{Acknowledgements}

This paper has been financially supported within the project entitled „SOCERT. Knowledge society, dynamism through research", contract number POSDRU/159/1. 5/S/132406. This project is co-financed by European Social Fund through Sectoral Operational Programme for Human Resources Development 2007-2013. Investing in people!"

\section{References}

Williamson, N. , Stampe-Knippel, A. , Weber T. , 2014, Corporate Social Responsibility National Public Policies in the European Union Compendium 2014, European Commission Directorate-General for Employment, Social Affairs and Inclusion, accessed online on 
05. 12. 2014 at http: //ec. europa. eu/social/BlobServlet?docld=12899\&langld=en

***, COM (2006) 136: Communication from the Commission to the European Parliament, the Council and the European Economic and Social Committee - Implementing the partnership for growth and jobs : making Europe a pole of excellence on corporate social responsibility, Comisia Europeană, Brussels 2006, accessed on line on 12. 12. 2014 at http: //eur-lex. europa. eu/legalcontent/EN/TXT/PDF/?uri=CELEX: 52006DC0136\&from=RO

***, COM (2011) 681: Communication from the Commission to the European Parliament, the Council, the Council and the European Economic and Social Committee - A renewed EU strategy 2011-14 for Corporate Social Responsibility, accessed online on 16. 12. 2014 at : http: //eur-lex. europa. eu/LexUriServ/LexUriServ. do?uri=COM: 2011: 0681: FIN: EN: PDF

***, National strategu for the promotion of social responsibility 2011-2016 [Strategia Națională de Promovare a Responsabilității Sociale 2011 - 2016], accesed online on 20. 12. 2014 at http: //www. sgg. ro/nlegislativ/docs/2011/05/2x4bdfjnwskv89h17pzq. pdf

**, Fiscal Code, Law no. 571/2003, last update through Law no. 123/2014, accessed online on 12. 12. 2014 at http: //static. anaf. ro/static/10/Anaf/Legislatie_R/Cod_fiscal_norme_2014. htm

Carroll, A. B. (1991). The pyramid of corporate social responsibility: Toward the moral management of organizational stakeholders. Business Horizons, no. 34, 39-48

Carroll, A. B. (1979). A three-dimensional conceptual model of Corporate Social Performance. Academy of Management Review, 4 (4), 497-505

McWilliams A. , \& Siegel, D. (2001). Corporate Social Responsibility: A Theory of the Firm Perspective. The Academy of Management Review 26 (1), 117-127

McWilliams A. , Siegel, D. , \& Wright, P. (2005) Corporate Social Responsibility: Strategic Implications. Rensselaer Working Papers in Economics, no. 0506, accessed online at http: //www. economics. rpi. edu/workingpapers/rpi0506. pdf on 06. 05. 2014

Saveanu, T. , Abrudan, M-M, Giurgiu, A. , Mester, L. , Bugnar, N. , 2014, Measuring Corporate Social Responsibility Practices of Micro And Small Enterprises - Pilot Study, in course of publication at Proceedings of The 8th International Management Conference "Management Challenges For Sustainable Development", November 6th-7th, 2014, Bucharest, Romania

Aguinis, H. , Glavas A. , 2012, What We Know and Don't Know About Corporate Social Responibility: A Review and Research Agenda, Journal of Management, vol. 38, no. 4, pp. 932-968

Acar, W. , Aupperle , K. E. , Lowy, R. M. , 2001, An empirical exploration of measures of social responsibility across the spectrum of organizational types, International Journal of Organizational Analysis, vol 9, no. 1, pg. 26-57

Banerjee, S. B. (2007). Corporate Social Responsibility: the good, the bad and the ugly. Critical Sociology, 34 (1), 51-79

Barth, V. R. , Wolff, F. \& \& Schmitt, K. (2007). CSR between Rhetoric and Reality. Ökologisches Wirtschaften, no. 4, 30-34.

Knox, S. \& Maklan, S. (2004). Corporate Social Responsibility: Moving Beyond Investment Towards Measuring Outcomes. European Management Journal, 22 (5), 508-16

Lindgreen, A. , Swaen, V. , Johnston, W. J. , 2009, Corporate Social Responsibility: An Empirical Investigation of U. S. Organizations, Journal of Business Ethics, vol. 85, pp. 303-323 